\title{
Significance of resection margin as a risk factor for local control of early stage breast cancer
}

\author{
Jiri Gatek ${ }^{a}$, David Vrana ${ }^{b, c, d}$, Lucie Lukesova ${ }^{b}$, Marketa Pospiskovae, Petr Vazan ${ }^{f}, B$ Bohuslav Melichar ${ }^{b}$
}

\begin{abstract}
Introduction. Breast conserving surgery combined with sentinel node biopsy represents currently the gold standard of treatment for early breast cancer. Although breast conserving surgery has been a widely accepted method for many years, there remain some highly controversial unresolved issues. The present analysis focused on the resection margin as one of the key factors for local control of the disease.
\end{abstract}

Methods. Patient disease free survival and overall survival were collected from patients undergoing breast conserving surgery from 2004 to 2009 at the Department of Surgery Atlas hospital Zlin, Czech Republic. All patients with resection margin less then $5 \mathrm{~mm}$ were re-resected to achieve this clear resection margin of $5 \mathrm{~mm}$ or more. Disease free survival (more specifically local relapse free survival, metastasis free survival and regional free survival) and overall survival were assessed.

Results. The data on 330 patients were analyzed and 286/330 cases had complete follow-up. After a median follow-up of 70 months, 7 patients with isolated local relapse were identified (2.44\%), 13 patients with distant metastasis without local relapse (4.54\%) and 2 patients with relapse in the axilla without local relapse in the breast $(0.7 \%)$.

Conclusion. The final decision about the extent of resection margin remains controversial but based on the data on local control presented here it seems reasonable to increase the criteria for a clear resection margin to $5 \mathrm{~mm}$.

Key words: breast cancer, resection margin, local relapse

Received: July 23, 2013; Accepted with revision: September 10, 2013; Available online: September 13, 2013

http://dx.doi.org/10.5507/bp.2013.067

${ }^{a}$ Department of Surgery, Atlas Hospital, Tomas Bata University in Zlin, Zlin, Czech Republic

${ }^{b}$ Department of Oncology, Faculty of Medicine and Dentistry, Palacky University Olomouc, Olomouc

cInstitute of Molecular and Translational Medicine, Faculty of Medicine and Dentistry, Palacky, University Olomouc and University Hospital Olomouc, Olomouc

${ }^{d}$ Toxicogenomics Unit, National Institute of Public Health, Prague

${ }^{e}$ Department of Oncology, Bata Hospital Zlin, Zlin

${ }^{f}$ Cytologic and Histopathologic Laboratory, Zlin

Corresponding author: David Vrana, e-mail: davvrana@gmail.com

\section{INTRODUCTION}

In patients with early stage breast cancer, breast conserving surgery followed by adjuvant radiotherapy represents a safe therapeutic alternative to the rather mutilating modified radical mastectomy ${ }^{1-2}$. This approach has been thoroughly investigated and is supported by many randomized studies. Today it is accepted as the gold standard $^{3-4}$. Adjuvant radiotherapy together with clear surgical resection margins both significantly decrease the local relapse rate and consequently, improve overall survival. They remain the principal factor that determines local relapse rate ${ }^{5}$. The primary objective of breast surgery is to obtain clear resection margins and, at the same time, achieve favorable cosmetic outcome. It is self-evident that surgery can significantly decrease patient quality of life ${ }^{6}$. Although the clinical team has to weigh carefully the cosmetic outcome, the biology of the tumor should also be considered. The decision on treatment strategy should be made by a multidisciplinary team including surgeon with training in oncological surgery, medical oncologist, radiation oncologist, radiologist and pathologist ${ }^{7}$. Despite the fact that for the treatment of early stage breast can- cer, radical mastectomy or modified radical mastectomy have been replaced by breast saving procedures, including quandrantectomy, lumpectomy and tumorectomy, these new techniques have raised some questions that have not yet been resolved. One of the principal issues is the extent of clear resection margins ${ }^{6}$. As mentioned above, a clear resection margin is one of the key factors determining local relapse and, at the same time, the cosmetic outcome. However, the exact extent of resection margin remains controversial. Positive resection margins, i.e. tumor cells present in resection line, represent a generally accepted indication for re-resection. However, in the case the resection margin is between $1 \mathrm{~mm}$ to $10 \mathrm{~mm}$, there are no clear recommendations and clinical teams are usually follow institutional guidelines ${ }^{7}$. The reason for the absence of consensus is the lack of randomized trials. The published data are often contradictory and confusing. Importantly, re-resections increase morbidity as well as the cost of the surgery. Local relapse rate is a reliable indicator of the long-term success of local management. At the Department of Surgery, Atlas Hospital, Zlin where this study was conducted, re-resection is routinely performed if the free resection margin achieved is less than 
$5 \mathrm{~mm}$. Although there is a strong feeling that this approach may impact the local relapse rate, the proof for this practice has been missing. At the same time, long term experience and patient feedback indicate that an acceptable cosmetic outcome may still be achieved in the majority of patients even if the $5 \mathrm{~mm}$ free resection margin rule is followed. It should be kept in mind that the final therapeutic outcome is the result of multidisciplinary collaboration between the specialists involved and even if the surgeon performs outstanding surgery, satisfactory outcome will not be achieved if radiotherapy or systemic adjuvant treatment are suboptimal, or vice versa ${ }^{7}$. The aim of this retrospective study was to investigate whether the $5 \mathrm{~mm}$ free resection margin has any impact on local relapse rate by comparing our data with that published on resection margin and local relapse rate.

\section{PATIENTS AND METHODS}

A prospective database at the Department of Surgery Atlas Hospital Zlin included breast cancer patients undergoing breast conserving surgery between the years 2004 and 2009. Breast cancer diagnosis was established before surgery with core-cut biopsy. Two principal breast-saving procedures performed included lumpectomy and quadrantectomy. In the case of lumpectomy, all six sides of the tumor specimen were assessed for resection margins. In the case of quadrantectomy, four sides were assessed as the fifth side is constituted of subcutaneous tissue and, in the case of close proximity, skin was also resected. The sixth side was pectoral fascia.

In all patients treated with breast saving surgery, sentinel node biopsy procedure or axillary dissection were performed, and in the case of metastasis in the sentinel lymph node, axillary dissection followed. In the case of non-palpable lesions, the surgeon was present during ultrasonography examination, marking on the skin the tumor location. The institutional guidelines mandate free resection margins of $5 \mathrm{~mm}$ or more because, as outlined above, these clear margin are believed to impact disease free survival. In the case the resection margin was positive for tumor cells or less than $5 \mathrm{~mm}$, a re-resection was completed. During the re-resection procedure, only affected cavity walls were re-resected. If re-resection did not achieve a free resection margin of $5 \mathrm{~mm}$ or more, mastectomy was subsequently performed. In all patients treated with breast saving surgery, adjuvant radiotherapy followed together with adjuvant chemotherapy or hormonal therapy according to the National Comprehensive Cancer Network guidelines. For adjuvant radiotherapy, linear accelerator Elekta synergy was used, using 3-D conformal planning, energy 6-18 MeV or Microselectron brachytherapy equipment for tumor bed boosting. The radiotherapy dose was 50 Gy for whole breast with additional boost for tumor bed (either $16 \mathrm{~Gy}$ in $2 \mathrm{~Gy}$ fractions using external beam radiotherapy or $12 \mathrm{~Gy}$ in 1 fraction using interstitial brachytherapy technique). All patients were followed for local and distant relapse over a 3 month interval during the first 3 years, at a 6 month interval in the next 2 years and then yearly. Clinical examination was performed during each visit, mammography yearly, liver ultrasound and chest X-ray yearly. Tumor markers CEA and $\mathrm{Ca}$ 15-3 were determined. Other tests and examinations were performed as clinically indicated. Disease free survival and overall survival data were collected after a minimum of a 5 year follow up. All patients lost from the database were contacted and questioned for cancer status. General practitioners were contacted in the case of patient death to find out the exact cause of death. However, since the information gathered from general practitioners and patients over the phone were considered unreliable, we have not included these patients in the final analysis for local relapse calculation despite the fact that all contacted patients were disease free.

\section{RESULTS}

The data on 330 breast cancer patients between 2005 and 2008 who underwent breast conserving surgery at the Department of Surgery, Atlas Hospital, Zlin, Czech Republic were analyzed in the present study. Most patients had T1 and T2 tumors and only one patient had T3 disease. Twenty-four patients with in situ carcinoma and 9 patients who underwent neoadjuvant chemotherapy before the surgical procedure were also included. The mean age of the patients was 59 years, ranging from 25 to 88 years. All patients met the general indication criteria for breast-conserving surgery at this department, including tumor size of less than $5 \mathrm{~cm}$ (one patient with marginal T3), no distant metastasis, no multicentric tumor, and willingness to undergo adjuvant radiotherapy. In the case of T3 tumors neoadjuvant chemotherapy was administered and 9 patients after neoadjuvant chemotherapy were included in the analysis. Tumor characteristics are summarized in Table 1. Lumpectomy was performed in 111 patients, and

Table 1. Tumor characteristics.

\begin{tabular}{lr}
\hline & Number of patients \\
\hline TNM Stage & \\
\hline 0 (TIS) & 19 \\
I & 101 \\
IIA & 63 \\
IIB & 33 \\
IIIA & 5 \\
IIB & 0 \\
IIIC & 9 \\
\hline Tumor Size & \\
\hline TIS & 24 \\
pT1mic & 2 \\
pT1a & 7 \\
pT1b & 69 \\
pT1c & 151 \\
pT2 & 76 \\
pT3 & 1 \\
\hline Total number & 330 \\
\hline
\end{tabular}

TIS - tumor in situ - non invasive cancer 
quadrantectomy in 219 patients. After careful assessment of tumor resection margin, the margin was less then $5 \mathrm{~mm}$ in 78 cases $(23.6 \%)$. Re-resection followed in these patients, and in 31 cases the re-resection specimen contained tumor cells. After s database search, we identified 286 patients (286/330) who were undergoing regular checkups or for whom the data on death or disease progression were available. Forty-four patients were lost to the followup due to movement to another city and hospital or for unknown reasons that obviated obtaining relevant clinical information on the status of the disease. As mentioned above, all patients lost to follow up, were contacted over the phone or the general practioner was contacted to find out the status of the disease. No cases of local or distant relapse were identified. The median follow-up of these patients was 70 months. After 70 months of follow up, 7 patients with isolated local relapse were identified $(2.4 \%)$, 13 patients with distant metastasis without local relapse $(4.5 \%)$, and 2 patients with regional relapse in the axilla without local relapse in the breast $(0.7 \%)$. After 5 years of follow-up, 6 local relapses (2.0\%), 11 distant relapses without local relapse $(3.9 \%)$ and 2 regional relapses in axillary nodes $(0.7 \%)$ were identified. After reviewing all seven patients with local relapse, we found that 2 patients had rejected the recommended adjuvant radiotherapy. All patients with local or regional (nodal) relapse were indicated for surgical therapy followed by radiotherapy in the case the radiotherapy was not performed as part of the primary breast cancer treatment. Only in one patient was local relapse followed early by distant metastasis, and systemic treatment was preferred over local treatment in this case.

\section{DISCUSSION}

The data show that meticulous attention to tumor resection margins during breast cancer surgery with reresection in the case of tumor resection margins of less than $5 \mathrm{~mm}$ as well as the use of adjuvant radiation therapy and systemic treatment, results in a very low local relapse rate. Among 286 patients with complete follow-up data, 7 patients with local relapse were identified after a median follow-up of 70 months which means the local relapse rate of $2.45 \%$. To be able compare our results with published data, a 5 year disease free interval was assessed. After 60 months of follow up, 6 local relapses were identified (2.0\%), 11 distant metastasis without local relapse (3.9\%), 2 regional relapses (in axillary lymph nodes) without local relapse $(0.7 \%)$. This relapse rate compared favorably with other published data. After analysis of 533 stage I and stage II breast cancer patients with close margins or negative margins and $7 \%$ local relapse rate at 8 years, Park et al. concluded that pathological margin status together with adjuvant therapy are the major predictors of local relapse ${ }^{8}$. Kunos et al. did a retrospective study of 341 stage I and II breast cancer patients to determine the rate of local relapse in relation to resection margin. After 54 months of follow-up, the recurrence rate was $1.8 \%$ in the case of tumor free margin more than $2 \mathrm{~mm}$ versus $8.4 \%$ in patients with tumor free margin between $0 \mathrm{~mm}$ and $2 \mathrm{~mm}$ (ref. ${ }^{9}$ ). Kreike et al. reported an ipsilateral recurrence rate of $9.3 \%$ after 10 years and $13.8 \%$ after 15 years allowing us to conclude that resection margin and lymphovascular invasion are the most important factors for local recurrence ${ }^{10}$. Mirza et al. observed $6 \%$ local relapse rate after 9 years in patients with stage I and II disease ${ }^{11}$. Miles et al. studied the impact of age on local control in 3064 breast cancer patients with a median follow up of 8.9 years. The local recurrence rate was $11.4 \%$ in patients younger than 40 years, $5.7 \%$ in patient group $40-49$ years, $6.2 \%$ in patients $50-59$ years of age, $60 \%$ in patients $60-69$ years old and $6.2 \%$ in patients older than 70 years ${ }^{12}$.

A weak point of the present analysis is a relatively high proportion of patients lost to follow-up that may evoke some uncertainty about the outcome in the whole cohort. However, the general practitioner or the patient was contacted in all these cases to rule out recurrent disease. Thus, the actual recurrence rate is even lower than in the cohort of patients with complete follow-up.

In breast cancer surgery, there are currently different recommendations regarding the resection margins, with some authors preferring the wider margins, underscoring the malignant nature of the disease, while others pointing out the growing importance of cosmetic outcome of the surgery. The recommended range of the clear resection margin between 1 and $10 \mathrm{~mm}$ is extremely wide, and guidelines agree only on the necessity of re-resection in case of positive margin ${ }^{7,13,14,15}$. In a previous study that aimed to determine what percentage of the cavity reresection specimen contain tumor cells in the case reresection is performed until clear resection margin of at least $5 \mathrm{~mm}$ is obtained, we reported that around 30\% of specimen re-resected to achieve $5 \mathrm{~mm}$ free resection margin will contain tumor tissue ${ }^{16}$. From these data, it is clear that resection margin less than $5 \mathrm{~mm}$ is definitely not sufficient to achieve tumor negative breast after surgical procedure ${ }^{17-18}$. The other important question is, however, whether obtaining free resection margin will have an impact on local recurrence rate and subsequently on overall survival of breast cancer patients ${ }^{19-27}$. All patients undergoing breast conserving surgery are indicated for adjuvant radiotherapy (considering that adjuvant radiotherapy may be omitted in older patients ${ }^{28}$ ). The effect of adjuvant radiotherapy for local tumor control is supported by a large number of randomized trials and its role currently seems to be unquestionable ${ }^{29}$. The outcome of early stage breast cancer patients is excellent with more then $90 \%$ surviving 5 years, but there may be still a space for improvement. This improvement may be achieved by more precise surgery aiming for wider clear resection margin that, together with adjuvant radiotherapy, could provide even better results as disease free survival and possibly overall survival. As mentioned above, after supportive data from a previous study we decided to evaluate the local relapse free survival in this group of patients in the case the clear resection margin $5 \mathrm{~mm}$ is achieved. We always have to keep in mind the importance of cosmetic outcome of breast surgery ${ }^{18}$. We also have to consider the fact that the isolated local relapse does not have to impact 
the overall survival since the local relapse may be successfully treated by local surgery or radiotherapy. On the other hand, local relapse remains a negative prognostic indicator $^{30-31}$. At the same time, local relapse may negatively affect the quality of life and, possibly, patient compliance during further follow-up or adjuvant treatment.

\section{CONCLUSION}

The strategy of $5 \mathrm{~mm}$ resection margin is associated with very low local recurrence rate. However further research is needed to provide clear recommendations regarding optimal free resection margin during breastconserving surgery.

\section{CONFLICT OF INTEREST STATEMENT}

Author's conflict of interest disclosure: None declared.

\section{REFERENCES}

I. Fisher B, Redmond C, Poisson R, Margolese R, Wolmark N, Wickerham L, Fisher E, Deutsch M, Caplan R, Pilch Y. Eight-year results of a randomized clinical trial comparing total mastectomy and lumpectomy with or without irradiation in the treatment of breast cancer. N Engl Med 1989;320:822-8

2. Veronesi U, Salvadori B, Luini A, Banfi A, Zucali R, Del Vecchio M, Saccozzi R, Beretta E, Boracchi P, Farante G. Conservative Treatment of Early Breast Cancer. Ann Surg March 1990;211:250-9.

3. Veronesi U, Cascinelli N, Mariani L, Greco M, Saccozzi R, Luini A, Aguilar M, Marubini E. Twenty -year follow-up of a randomized study comparing breast - conserving surgery with radical mastectomy for early breast cancer. N Engl J Med 2002;347:1227-32.

4. Fisher B, Anderson S, Bryant J, Margolese RG, Deutsch M, Fisher ER, Jeong $\mathrm{JH}$, Wolmark N. Twenty-year follow-up of a randomized trial comparing total mastectomy, lumpectomy and lumpectomy plus irradiation for the treatment of invasive breast cancer. N Engl J Med 2002;347:1233-41.

5. Fisher B, Dignam J, Wolmark N, Mamounas E, Costantino J, Poller W, Fisher ER, Wickerham DL, Deutsch M, Margolese R, Dimitrov N Kavanah M. Lumpectomy and radiation therapy for the treatment of intraductal breast cancer: findings from National Surgical Adjuvant Breast and Bowel Project B-17. J Clin Oncol 1998;16:441-52.

6. Singletary SE. Surgical margins in patients with early-stage breast cancer treated conservation therapy. Am J Surg 2002;184:383-93.

7. Taghian A, Mohiuddin M, Jagsi R, Goldberg S, Ceilley E, Powell S. Current perception regarding surgical margin status after breastconserving therapy: results of a survey. Ann Surg 2005;24:629-39.

8. Park CC, Mitsumori M, Nixon A, Recht A, Connolly J, Gelman R, Silver B, Hetelekidis S, Abner A, Harris JR, Schnitt SJ. Outcome at 8 years after breast-conserving surgery and radiation therapy for invasive breast cancer: influence of margin status and systemic therapy on local recurrence. J Clin Oncol 2000;18(8):1668-75.

9. Kunos C, Latson L, Overmoyer B, Silverman P, Shenk R, Kinsella T, Lyons J. Breast-conservation surgery achieving or $2 \mathrm{~mm}$ tumor-free Margins results in decreased local-regional recurrence rates. Breast Journal 2006;12:28-36.

10. Kreike B, Hart AA, van de Velde $T$, Borger J, Peterse $H$, Rutgers $E$, Bartelink $\mathrm{H}$, van de Vijver MJ. Continuing risk of ipsilateral breast relapse after breast-conserving therapy at long-term follow-up. Int J Radiat Oncol Biol Phys 2008;71(4):1014-21.

11. Mirza NQ, Vlastos G, Meric F, Buchholz TA, Esnaola N, Singletary SE, Kuerer HM, Newman LA, Ames FC, Ross MI, Feig BW, Pollock RE, McNeese M, Strom E, Hunt KK. Predictors of locoregional Recurrence among Patients with early-stage breast cancer treated with breastconserving therapy. Ann Surg Oncol 2001;9(3):226-65.

12. Miles RC, Gullerud RE, Lohse CM, Jakub JW, Degnim AC, Boughey $J C$. Local recurrence after breast-conserving surgery: multivariable analysis of risk factors and the impact of young age. Ann Surg Oncol 2012;19(4):1153-9.

13. Houssami N, Macaskill P, Marinovich ML, Dixon JM, Irwig L, Brennan $\mathrm{ME}$, Solin LJ. Meta - analysis of the impact of surgical margins on Local recurrence in women with early-stage invasive breast cancer treated with breast conserving therapy. Eur J Cancer 2010;463:231932.

14. Schwartz GF, Veronesi U, Clough KB, Dixon JM, Fentiman IS Heywang-Köbrunner SH, Holland R, Hughes KS, Mansel RE, Margolese R, Mendelson EB, Olivotto IA, Palazzo JP, Solin LJ, Consensus Conference Committee. Proceedings of the Consensus Conference on Breast Conservation, April 28-May 1,2005, Milan, Italy. Cancer 2006;107:242-50.

15. Kaufmann M, Morrow M, Minckwitz G. Locoregional Treatment of Primary Breast Cancer. Cancer 2010;1:184-91.

16. Gatek J, Vrana D, Melichar B, Vazan P, Kotocova K, Kotoc J, Dudesek $B$, Hnatek L, Duben J. Significance of the resection margin and risk factors for close or positive resection margin in patients undergoing breast-conserving surgery. Journal of BUON 2012;17(3):452-6.

17. Kunos C, Latson L, Overmoyer B, Silverman P, Shenk R, Kinsella T, Lyons J. Breast-conservation surgery achieving or $2 \mathrm{~mm}$ tumor-free Margins results in decreased local-regional recurrence rates. Breast Journal 2006;12:28-36.

18. Fedorcik GG, Sachs R, Goldfarb MA. Oncologic and anesthetic results following breast-conserving therapy with $0,5 \mathrm{~cm}$ margins in 100 consecutive patients. The Breast Journal 2006;12(3):208-11.

19. Meric F, Mirza NQ, Vlastos G, Buchholz TA, Kuerer HM, Babiera GV, Singletary SE, Ross MI, Ames FC, Feig BW, Krishnamurthy $S$, Perkins GH, McNeese MD, Strom EA, Valero V, Hunt KK. Positive Surgical Margins and Ipsilateral Breast Tumor Recurrence Predict Disease-Specific Survival after Breast -Conserving Therapy. Cancer 2003;(97):926-33.

20. Smitt MC, Nowels KW, Zdeblick MJ, Jeffrey S, Carlson RW, Stockdale FE, Goffinet DR. The Importance of the Lumpectomy Surgical Margin Status in Long Term Results of Breast Conservation. Cancer 1995;(76):259-67.

21. Anscher MS, Jones P, Prosnitz LR, Blackstock W, Hebert M, Reddick R, Tucker A, Dodge R, Leight G Jr, Iglehart JD. Local Failure and Margin Status in Early - Stage Breast Carcinoma Treated with Conservation Surgery and Radiation Therapy. Ann Surg 1993;218:22-8.

22. Cellini C, Hollenbeck ST, Christos P, Martins D, Carson J, Kemper S, Lavigne E, Chan E, Simmons R. Factor associated with residual breast cancer after re-excision for close or positive margins. Ann Surg Oncol 2004;11:915-20.

23. Landheer ML, Klinkenbijl JH, Pasker-de Jong PC, Wobbes T. Residual disease after excision of non-palpable breast tumors: analysis of tumor characteristics. Eur J Surg Oncol 2004;30:824-8.

24. Tartter PI, Kaplan J, Bleiweiss I, Gajdos C, Kong A, Ahmed S, Zapetti D. Lumpectomy margins, reexcision, and local recurrence of breast cancer. Am J Surg 2000;179:81-5.

25. Luu HH, Otis CN, Reed WP Jr, Garb JL, Frank JL. The unsatisfactory margin in breast cancer surgery. Am J Surg 1999;178:362-6.

26. Mechera R,Viehl C, Oertli D. Factors predicting in-breast tumor recurrence after breast - conserving surgery. Breast Cancer Treat 2009;116:171-7.

27. Meric F, Mirza NQ, Vlastos G, Buchholz TA, Kuerer HM, Babiera GV, Singletary SE, Ross MI, Ames FC, Feig BW, Krishnamurthy S, Perkins GH, McNeese MD, Strom EA, Valero V, Hunt KK. Positive Surgical Margins and Ipsilateral Breast Tumor Recurrence Predict Disease-Specific Survival after Breast -Conserving Therapy. Cancer 2003;97:926-33.

28. Vrana D, Gatek J, Lukesova L, Vazan T, Melichar B, Pospiskova M, Svach I. Omission of adjuvant radiation therapy in elderly patients with low risk breast cancer undergoing breast-conserving surgery two center experience. Biomed Pap Med Fac Univ Palacky Olomouc Czech Repub. 2013 May 3. doi: 10.5507/bp.2013.032. [Epub ahead of print]

29. Santiago RJ, Wu L, Harris E, Fox K, Schultz D, Glick J, Solin LJ. Fifteenyear results of breast-conserving surgery and definitive irradiation 
for Stage I and II breast carcinoma: the University of Pensylvania experience. Int J Radioation Oncology Phys 2004;58:233-40.

30. Vicini FA, Kestin L, Huang R, Martinez A. Does local Recurrence affect the rate of distant metastases and survival in patients with earlystage breast carcinoma treated with breast conserving therapy? Cancer 2003;97:910-9.
31. Komoike $Y$, Akiyama F, lino $Y$, Ikeda T, Akashi-Tanaka S, Ohsumi $S$, Kusama M, Sano M, Shin E, Suemasu K, Sonoo H, Taguchi T, Nishi T, Nishimura R, Haga S, Mise K, Kinoshita T, Murakami S, Yoshimoto M, Tsukuma H, Inaji H. Ipsilateral breast tumor recurrence (IBTR) after breast conserving treatment for early breast cancer: risk factors and impact on distant metastases. Cancer 2006;106:35-41. 